ORIGINAL ARTICLE

\title{
Participants' Opinion about Conduct of Morbidity and Mortality Conferences in Surgical Practice in a Tertiary Hospital, Ethiopia
}

\author{
Berhanetsehay Teklewold ${ }^{1}$, Tilahun Deresse ${ }^{1}$, Goytom Kinfe ${ }^{1}$, Henok Teshome ${ }^{1}$
}

\author{
OPEN ACCESS \\ Citation: Berhanetsehay Teklewold, \\ Tilahun Deresse, Goytom Kinfe, Henok \\ Teshome. Participants' Opinion about \\ Conduct of Morbidity and Mortality \\ Conferences in Surgical Practice at St. \\ Paul's Hospital Millennium Medical \\ College, Addis Ababa, Ethiopia. Ethiop J \\ Health Sci. \\ 2020;30(3):355.doi:http://dx.doi.org/10.431 \\ 4/ejhs.v30 i3.6 \\ Received: November 11, 2019 \\ Accepted: January 2, 2020 \\ Published: May 1, 2020 \\ Copyright: (C2020 Farzad G., et al. This \\ is an open access article distributed under \\ the terms of the Creative Commons \\ Attribution License, which permits \\ unrestricted use, distribution, and \\ reproduction in any medium, provided the \\ original author and source are credited. \\ Funding: Nil \\ Competing Interests: The authors \\ declare that this manuscript was approved \\ by all authors in its form and that no \\ competing interest exists. \\ Affiliation and Correspondence: \\ ${ }^{1}$ St. Paul's Hospital Millennium \\ Medical College (SPHMMC), \\ Addis Ababa, Ethiopia \\ *Email: hennyteshe@yahoo.com or \\ henokteshome2@gmail.com
}

ABSTRACT

BACKGROUND: Morbidity and mortality conference has both educational and quality improvement purposes. However clear evidences for the effectiveness of the morbidity and mortality conferences in improving patient safety is lacking.

METHODS: A facility based cross sectional study was conducted at St. Paul's Hospital Millennium Medical College, Addis Ababa, Ethiopia, to assess participants' opinion on benefits and functioning of morbidity and mortality conferences. Univariate analysis was used to determine the influence of professional type on participants' opinion about the morbidity and mortality conferences.

RESULT: A total of 98 participants completed the survey. The majority of the participants agreed that there was a structured system of case identification (67.3\%), meeting format (72.4\%), the conferences were conducted every month (79.6\%), it is blame free (71.4\%) and system of care was focus of discussion (70\%). Most (88.8\%) participants agreed that the conferences were important for improvement of patient safety and quality of care, whereas $67.3 \%$ of the participants believed that there is no written term of reference and prior dissemination of agendas. Only 40\% agreed that there is multidisciplinary team involvement. Fifty one percent of them disagreed that there is a follow up on the implementation of the forwarded recommendations.

CONCLUSION: Even though the majority of the participants were satisfied with the mortality and morbidity conferences, most disagreed on the presence of written term of reference, earlier dissemination of agendas, multidisciplinary team involvement and follow up on the implementation of the forwarded recommendations.

KEYWORDS: Morbidity and Mortality Conferences, Patient Safety, Quality Improvement

\section{INTRODUCTION}

Morbidity and mortality conferences (MMCs) were established in the United States at the beginning of the $20^{\text {th }}$ century. Since then, it has become a relevant part of physician education (1).

With the emergence of the management of patient safety in the healthcare system in the 1990s, several authors suggested 
that MMCs could be conducted to improve the quality and safety of healthcare (2). Therefore, MMCs are now widely implemented in hospitals, but evidence of their effectiveness in improving patient safety is lacking. Numerous authors have found that the characteristics of MMCs varied greatly with variations in their goals, their structures, and their processes $(3,4,5)$. MMC is a deep-rooted tradition in surgery and is adopted by many other medical specialties, aiming to serve both educational and quality improvement (QI) purposes $(3,6)$.

The best evidence of the effectiveness of MMCs would be to demonstrate an effect on a patient-related outcome. However, this approach presents methodological issues, and very few studies have concluded in favour of the significant effect of MMCs on a clinical outcome $(7,8)$. Considering the wide variety of situations, choosing and using a patient-related outcome is difficult. Where this is possible, the low incidence of specific events would lead to a lack of statistical power (9). In this context, several authors estimated the effectiveness of MMCs indirectly through the perception of the participants in these meetings $(4,10,11)$.

The conduct of MMCs was started in 2013, at St. Paul's Hospital Millennium Medical College (SPHMMC), Department of Surgery. Since then, it is being conducted monthly, and senior residents are responsible for the data collection, analysis and presentation. In the conferences, the monthly inpatient activity, complications and deaths are discussed.

This study focuses on the functioning of MMCs, the perception of their benefits by the participants, especially concerning healthcare quality and safety improvement, the personal motivations of participants and suggestions for improvement.

Though MMC sessions are traditions in surgery since the introduction of modern medicine to our country, to our knowledge, there is no study done in Ethiopia to assess the benefits of this sessions. The objective of this study was thus to assess participants' opinion about the format, conduct, perceived benefits and outcome of surgical mortality and morbidity conferences at St. Paul's Hospital Millennium Medical College.

\section{METHODS AND MATERIALS}

A facility based cross sectional study was done at St. Paul's Hospital Millennium Medical College, in Addis Ababa, Ethiopia, from June 1, 2019 till August 31, 2019. St. Paul's Hospital Millennium Medical College is a teaching hospital for both undergraduate and postgraduate studies with 110 surgical beds.

MMC sessions were held monthly in the Department of Surgery. In the meetings, senior residents analyze and present outcome and average hospital stay of all cases clustered with similar diagnosis. Details of cases with adverse events were also presented and among them, one or two selected cases were discussed in depth. The department head or the postgraduate studies coordinator select cases with management pitfall or educational cases. The meetings were 40 minutes to one hour long and were moderated by the department head.

All surgeons, residents and medical students who were available during the study time and had attended at least two sessions of MMC were included in the study. Professionals who attended the session only once were excluded from the study.

A pre-tested structured questionnaire was used. There was an open-ended question at the end, to get participants' opinion about areas of improvement, and similar recommendations were later categorized and reported. The data was collected by the investigators.

The data was analyzed using SPSS version 23. Univariate analysis was used to determine the influence of professional type on participants' opinion. Statistical test chi square at 0.05 level of significance was used. A written ethical clearance letter was given from SPHMMC's institutional review board. The data acquired was used only for the study and patients' information used in the research was kept confidential.

\section{RESULTS}

Sociodemographic characteristics: Eighteen consultants, 65 surgical residents, 7 GPs and 8 Medical interns received the questionnaire, and all of them completed the survey. About $61.9 \%$ of the participants attended more than five sessions and the remaining attended 2-5 sessions.

DOI: http://dx.doi.org/10.4314/ejhs.v30i3.6 
Format of MMC: More than two third of the participants agreed that there was a structured system of case identification $(67.3 \%)$, meeting format $(72.4 \%)$ and the conferences were conducted regularly (79.6\%), whereas $67.3 \%$ of the participants believed that there were no written terms of reference (TOR) for the conduction of the meeting and that there was no prior dissemination of agendas. Only 40\% agree that there was multidisciplinary team involvement (Table 1).

Table 1: Participants' opinion on the Format of Mortality and Morbidity Conference, at St. Paul's Hospital Millennium Medical College, Department of surgery.

\begin{tabular}{|c|c|c|c|c|c|c|}
\hline \multirow[t]{2}{*}{ MMC Format } & \multicolumn{5}{|c|}{ Frequency (Percent) } & \multirow[t]{2}{*}{ Total } \\
\hline & $\begin{array}{l}\text { Entirely } \\
\text { Agree }\end{array}$ & $\begin{array}{l}\text { Partially } \\
\text { Agree }\end{array}$ & Neutral & $\begin{array}{l}\text { Partially } \\
\text { Disagree }\end{array}$ & $\begin{array}{l}\text { Entirely } \\
\text { Disagree }\end{array}$ & \\
\hline $\begin{array}{ll}\text { Structured } & \text { Case } \\
\text { Identification } & \end{array}$ & $22(22.4)$ & $44(44.9)$ & $2(2.0)$ & $21(21.4)$ & $9(9.2)$ & 98 \\
\hline $\begin{array}{l}\text { Structured Meeting } \\
\text { Format }\end{array}$ & $22(22.4)$ & $49(50)$ & $0(0)$ & 19(19.4) & $8(8.2)$ & 98 \\
\hline Regularity & $47(48)$ & $31(31.6)$ & $4(4.1)$ & $14(14.3)$ & $2(2.0)$ & 98 \\
\hline $\begin{array}{l}\text { Agenda } \\
\text { dissemination }\end{array}$ & $12(12.2)$ & $17(17.3)$ & $5(5.1)$ & $17(17.3)$ & $47(48.0)$ & 98 \\
\hline $\begin{array}{l}\text { Multidisciplinary } \\
\text { team }\end{array}$ & $7(7.1)$ & $33(33.7)$ & $3(3.1)$ & $21(21.4)$ & $34(34.7)$ & 98 \\
\hline Written TOR & $9(9.2)$ & $23(23.5)$ & 11(11.2) & $20(20.4)$ & $35(35.7)$ & 98 \\
\hline
\end{tabular}

Conduct of MMC sessions: Most of the respondents agreed entirely $(25.5 \%)$ or partially $(48 \%)$ that there is a consistent case presenting format, and also, most agreed that the conference was blame free $(29.6 \%$, and $41.8 \%$ entirely and partially agreed respectively). The $22 \%$ entirely agreed and the $48.0 \%$ partially agreed that system of care is a focus of discussion.
Perceived benefits of the participants from the MMC sessions: More than two third of the respondents agreed totally or partially for each of the benefit proposed, except improvement of the relationship between medical and paramedical teams which was found to be $(58.2 \%)$. The highest agreement among the participants was seen for improvement of patient safety and quality of care with $(88.8 \%)$ each (Table 2$)$.

Table 2: Participants' opinion on the benefits of Mortality and Morbidity Conference, at St. Paul's Hospital Millennium Medical College, Department of surgery.

\begin{tabular}{|c|c|c|c|c|c|c|}
\hline \multirow[t]{3}{*}{ MMC Benefits } & \multicolumn{5}{|c|}{ Frequency (Percent) } & \multirow[t]{3}{*}{ Total } \\
\hline & Entirely & Partially & Neutral & Partially & Entirely & \\
\hline & Agree & Agree & & Disagree & Disagree & \\
\hline Educational & $42(42.9)$ & $35(35.7)$ & $3(3.1)$ & $13(13.3)$ & $5(5.1)$ & 98 \\
\hline Improves quality of care & $52(53.1)$ & $35(35.7)$ & $2(2.0)$ & $7(7.1)$ & $2(2.0)$ & 98 \\
\hline Improve patient safety & $55(56.1)$ & $32(32.7)$ & $2(2.0)$ & $8(8.2)$ & $1(1.0)$ & 98 \\
\hline Standardizes service & 44(44.9) & $34(34.7)$ & $2(2.0)$ & $15(15.3)$ & $3(3.1)$ & 98 \\
\hline Continued education & $41(41.8)$ & $37(37.8)$ & $5(5.1)$ & $12(12.2)$ & $3(3.1)$ & 98 \\
\hline Helps to apply Guidelines & $36(36.7)$ & $32(32.7)$ & $3(3.1)$ & $15(15.3)$ & $12(12.2)$ & 98 \\
\hline $\begin{array}{l}\text { Improve Functioning of the } \\
\text { department }\end{array}$ & $46(46.9)$ & $38(38.8)$ & $4(4.1)$ & $7(7.1)$ & $3(3.1)$ & 98 \\
\hline Improve Team work & $46(46.9)$ & $30(30.6)$ & $3(3.1)$ & $14(14.3)$ & $5(5.1)$ & 98 \\
\hline $\begin{array}{l}\text { Improve medical } \\
\text { paramedical relation }\end{array}$ & $29(29.6)$ & $28(28.6)$ & $7(7.1)$ & $21(21.4)$ & $13(13.3)$ & 98 \\
\hline Improve Safety Culture & $37(37.8)$ & $42(42.9)$ & $3(3.1)$ & $10(10.2)$ & $6(6.1)$ & 98 \\
\hline Discus Collective Errors & $42(42.9)$ & $40(40.8)$ & $4(4.1)$ & $8(8.2)$ & $4(4.1)$ & 98 \\
\hline
\end{tabular}

DOI: http://dx.doi.org/10.4314/ejhs.v30i3.6 
Outcome of MMC: More than one third of the participants did not agree to the proposed outcomes of the sessions. About $51 \%$ of them disagreed that there is a follow up on the implementation of the forwarded recommendations for improvement (Table 3).

Table 3: Participants' opinion on the outcome of Mortality and Morbidity Conference, at St. Paul's Hospital Millennium Medical College, Department of surgery

\begin{tabular}{|c|c|c|c|c|c|c|}
\hline \multirow[t]{3}{*}{ MMC Outcomes } & \multicolumn{5}{|c|}{ Frequency (Percent) } & \multirow[t]{3}{*}{ Total } \\
\hline & Entirely & Partially & Neutral & Partially & Entirely & \\
\hline & Agree & Agree & & Disagree & Disagree & \\
\hline $\begin{array}{l}\text { Assign time line for improvement of } \\
\text { recommendations }\end{array}$ & $21(21.4)$ & $41(41.8)$ & $5(5.1)$ & $20(20.4)$ & $11(11.2)$ & 98 \\
\hline $\begin{array}{l}\text { Assign individuals to carry out } \\
\text { recommendations }\end{array}$ & $12(12.2)$ & $42(42.9)$ & $3(3.1)$ & $28(28.6)$ & 13(13.3) & 98 \\
\hline Detailed record keeping & $22(22.4)$ & $32(32.7)$ & $5(5.1)$ & 21(21.4) & $18(18.4)$ & 98 \\
\hline Audit of previous MMC & $27(27.6)$ & $26(26.5)$ & $7(7.1)$ & $26(26.5)$ & $12(12.2)$ & 98 \\
\hline $\begin{array}{l}\text { Follow implementation } \\
\text { recommendations }\end{array}$ & $18(18.4)$ & $30(30.6)$ & $7(7.1)$ & $31(31.6)$ & $12(12.2)$ & 98 \\
\hline $\begin{array}{l}\text { Ensure recommendations are made } \\
\text { for each case }\end{array}$ & $24(24.5)$ & $41(41.8)$ & $4(4.1)$ & $21(21.4)$ & $8(8.2)$ & 98 \\
\hline
\end{tabular}

Personal motivations for the attendees: More than $80 \%$ of the attendee's personal motivations to participate in MMCs were most often related to improvement of individual professional and team practices and improvement of the department's functioning (Table 4).

Table 4: Participants' opinion on their reason to attend Mortality and Morbidity Conference, at St. Paul's Hospital Millennium Medical College, Department of surgery

\begin{tabular}{|c|c|c|c|c|c|c|}
\hline \multirow{2}{*}{$\begin{array}{l}\text { Reasons to attend } \\
\text { MMC }\end{array}$} & \multicolumn{5}{|c|}{ Frequency (Percent) } & \multirow[t]{2}{*}{ Total } \\
\hline & $\begin{array}{l}\text { Entirely } \\
\text { Agree }\end{array}$ & $\begin{array}{l}\text { Partially } \\
\text { Agree }\end{array}$ & Neutral & $\begin{array}{l}\text { Partially } \\
\text { Disagree }\end{array}$ & $\begin{array}{l}\text { Entirely } \\
\text { Disagree }\end{array}$ & \\
\hline $\begin{array}{l}\text { Mandatory } \\
\text { requirement }\end{array}$ & $25(25.5)$ & $40(40.8)$ & $8(8.2)$ & $10(10.2)$ & $15(15.3)$ & 98 \\
\hline Social interaction & $16(16.3)$ & $42(42.9)$ & $7(7.1)$ & $22(22.4)$ & 11(11.2) & 98 \\
\hline $\begin{array}{l}\text { Improve } \\
\text { professional } \\
\text { Practice }\end{array}$ & $39(39.8)$ & $41(41.8)$ & $6(6.1)$ & $8(8.2)$ & $4(4.1)$ & 98 \\
\hline Improve team work & $44(44.9)$ & $40(40.8)$ & $2(2.0)$ & $8(8.2)$ & $4(4.1)$ & 98 \\
\hline $\begin{array}{l}\text { Improvement in the } \\
\text { functioning of the } \\
\text { department }\end{array}$ & $44(44.9)$ & $40(40.8)$ & $3(3.1)$ & $8(8.2)$ & $3(3.1)$ & 98 \\
\hline
\end{tabular}

Participants' recommendation on areas of Improvement: The majority of the participants agreed to increase the participation of seniors (85.7\%), department head (87.7\%), other specialists $(88.8 \%)$ and, paramedics $(86.8 \%)$ in the conferences. They also agreed that case selection $(90.8 \%)$ and case analysis methods $(94.6 \%)$ should improve. However, more than half $(52.1 \%)$ of the respondents disagreed to increase the number of MMC sessions to more than one per month (Table $5)$.
There was no large deviation between professions on their proportion of agreement for the above parameters except on the perception that the conferences were blame free. Majority (94.4\%) of seniors and all GPs agreed that the MMCs were blame free, but only $66.2 \%$ of residents and $37.5 \%$ of interns agreed on that $(\mathrm{P}=0.01)$.

Forty of the respondents $(40.8 \%)$ wrote comments and suggestions at the end of completing the semi-structured questionnaire. Twenty mentioned the importance of MMCs and three

DOI: http://dx.doi.org/10.4314/ejhs.v30i3.6 
others appreciated the high rate of physician especially consultant attendance. Most of them (60\%) emphasized a low participation rate for several professional categories, specifically anesthetists, ward/OR nurses, other specialists and hospital administrators. Six comments highlighted the lack of good time management with most of them being unduly prolonged. Twenty one professionals described an open and friendly environment, whereas eight described a blameful environment with conflicts. The participants emphasized their comment to improve follow-up on the implementation of the recommendations and dissemination of areas of discussion before the MMC.

Finally, the following points are raised as areas of improvement by individual participants: avoid seminars schedules next to MMCs, improve data recording methods and chart documentation, include detachment site reports on the conference, always involve the managing team when a case is discussed, assign junior residents to help the senior resident during data collection, avail a punishment and reward system, department head should lead the session, and produce action plans for identified gaps.

Table 5: Participants' recommendation on areas of improvement in Mortality and Morbidity Conference, at St. Paul's Hospital Millennium Medical College, Department of surgery.

\begin{tabular}{|c|c|c|c|c|c|c|}
\hline \multirow{3}{*}{$\begin{array}{l}\text { Areas of } \\
\text { improvement }\end{array}$} & \multicolumn{5}{|c|}{ Frequency (Percent) } & \multirow[t]{3}{*}{ Total } \\
\hline & Entirely & Partially & Neutral & Partially & Entirely & \\
\hline & Agree & Agree & & Disagree & Disagree & \\
\hline $\begin{array}{l}\text { Increase } \\
\text { frequency }\end{array}$ & $15(15.3)$ & $26(26.5)$ & $6(6.1)$ & $23(23.5)$ & $28(28.6)$ & 98 \\
\hline $\begin{array}{l}\text { Increase Senior } \\
\text { Participation }\end{array}$ & $55(56.1)$ & $29(29.6)$ & $4(4.1)$ & $7(7.1)$ & $3(3.1)$ & 98 \\
\hline $\begin{array}{l}\text { Increase } \\
\text { department head } \\
\text { Participation }\end{array}$ & $55(56.1)$ & $31(31.6)$ & $1(1.0)$ & $7(7.1)$ & $4(4.1)$ & 98 \\
\hline $\begin{array}{l}\text { Increase invited } \\
\text { other specialists }\end{array}$ & $68(69.4)$ & $19(19.4)$ & $2(2.0)$ & $5(5.1)$ & $4(4.1)$ & 98 \\
\hline $\begin{array}{l}\text { Increase } \\
\text { Paramedics } \\
\text { participation }\end{array}$ & $62(63.3)$ & $23(23.5)$ & $5(5.1)$ & $3(3.1)$ & $5(5.1)$ & 98 \\
\hline $\begin{array}{l}\text { Improve case } \\
\text { selection method }\end{array}$ & $61(62.2)$ & $28(28.6)$ & $3(3.1)$ & $4(4.1)$ & $2(2.0)$ & 98 \\
\hline $\begin{array}{l}\text { Improve case } \\
\text { analysis method }\end{array}$ & $67(68.4)$ & $26(26.5)$ & $3(3.1)$ & $1(1.0)$ & $1(1.0)$ & 98 \\
\hline
\end{tabular}

\section{DISCUSSION}

Our study found that $67.3 \%$ of the participants believed that there is no written terms of reference (TOR) for the conduction of the meeting and that there is no prior dissemination of agendas. If there is no clear written TOR, MMC can differ in format and content from session to session depending on the variation of responsible individuals. Lack of prior dissemination of agendas makes the attendees unprepared and decreases the quality of the discussion. All this will limit the effectiveness of
MMCs for improving patient safety and quality of care. In a similar study conducted by A. Lecoanet et al., the existence of a written TOR $(p=0.05)$, the use of a standardized case presentation $(\mathrm{p}=0.049)$, and prior dissemination of the meeting agenda $(p=0.02)$ were associated with the perception of morbidity and mortality conference effectiveness (12).

Most of the respondents agreed that the conferences were blame free $(71.4 \%)$ and system of care is a focus of discussion $(60 \%)$. This is important for creating a smooth teaching

DOI: http://dx.doi.org/10.4314/ejhs.v30i3.6 
environment and should be strengthened more. Similar to our study, in the study conducted by A. Lecoanet et al., most of the respondents agreed, totally or partially that the meeting was nonblaming $(86.1 \%, n=589)(12)$. In another similar study conducted by Gonzalo JD., among 166 respondents, 93\% agreed that discussion of complications or adverse events at MMCs are without "blame" (13). Higginson J et al. studied participants' observations of MMCs and all interviewees stressed that MMCs should be blamefree to facilitate improvement and accountability, although some were not sure that this was true of their meetings (14). More than two third of the respondents had agreed on the proposed benefits of the MMC, but only $58.2 \%$ of the participants agree that the MMC helps to improve the relationship between medical and paramedical teams. This is mainly due to the fact that paramedics did not regularly attend the conferences. Only $40.8 \%$ of the participants agreed that the conference is multidisciplinary involving other specialists and paramedics. Failure to elicit the input of all staff involved in a case can result in poor understanding of underlying factors that contributed to the incident. This makes MMCs less likely to mitigate underlying factors which limits their effectiveness for improving patient safety and quality of care. Similarly in the above study conducted by A. Lecoanet et al., only $60 \%$ of the respondents agreed totally or partially agreed that MMC are important for improvement of the relationship between medical and paramedical teams (12).

More than one third of the participants did not agree that individuals and timeline were assigned to carry out recommendations, detailed record keeping were kept, audit of previous MMC were done and recommendations were made for each case. About $51 \%$ of them believed that there is no follow up on the implementation of the forwarded recommendations for improvement. Making recommendations for each case, assigning individuals and timeline to carry out recommendations and following the implementation of recommendations will prevent recurrence of similar events as recommended by Accreditation Council for Graduate Medical Education (ACGME), which is the major objective of the MMC. Well-kept MMC records will help participants to do researches, which will enrich the medical literature, enhance medical education along with all ACGME core competencies, and advance sharing of the lessons learned among all medical providers (15). A survey of 15 general surgical units' MMCs in West of Scotland found that only 3 units had a clear plan to follow-up the recommendation made at the meeting and records are kept in 13 of the 15 units (16). In another survey done by Gaelle evaluating 24 MMCs, a person in charge and a timeline were rarely designated $(32.9 \%)$, and only $25 \%$ of departments started the meeting with a review of how previous corrective measures had been implemented (17).

The majority of the participants wanted improvement on senior $(85.7 \%)$, department head (87.7\%), paramedics $(86.8 \%)$ and other specialists (88.8\%) participations like the French study conducted by A. Lecoanet et al. (12). Getting input from all staff involved in the care of cases is important to fully understand what actually occurred during an event. So, due emphasis should be given to increasing the participation of different specialists and paramedics. A study conducted at trauma-surgical intensive care unit at Harborview Medical Center emphasized that multidisciplinary case review process provides a forum for clear communication between members of the patient care team with the goal of developing best practices, system changes, and policies that will minimize risks for the patients and provide education for the staff (18). Another survey of MMCs of West of Scotland found similar under representation of all teams. Among studied 15 general surgical units, MMCs are attended by other departments in five units and nursing staff in only one unit (16). Another survey done by Gaelle evaluating 24 MMCs found that physicians from outside the department and paramedical staff were involved in $37.5 \%$ and $33.3 \%$ of the sessions respectively (17).

More than $90 \%$ of the participants recommended improvement on case selection and case analysis methods. Uniformity and standardization of case selection methods can be achieved by developing guideline/standard format and by establishing an MMC committee that will guide the presenters on case selection and analysis according to a set standard. A study conducted by

DOI: http://dx.doi.org/10.4314/ejhs.v30i3.6 
Michael J. et al. identified that residents demonstrated improved ability to specify the causes of complications after implementation of standard format (mean rating, 4.56 vs 3.11, p < 0.05 ) as well as to identify specific ways to avoid the complications in the future (mean, 4.31 vs 3.42 , $\mathrm{p}<0.05)(19)$.

More than half $(52.1 \%)$ of the respondents disagreed on the increment of the number of MMC sessions to more than one per month even though ACGME recommend a weekly MMC. Discussing complications and deaths in the form of MMC every week, in addition to morning sessions, gives the opportunity for early intervention and minimizes the burden of cases per MMC (15). In an England study on participant observations of MMCs, participants found weekly meetings helpful as the cases were still fresh in their minds and the small number allowed time for in-depth discussion. However, the chair of a meeting that met monthly suggested that weekly meetings were less 'special' and would lose their impact (14).

Six participant comments highlighted the lack of good time management with most of them being unduly prolonged and affecting the hospital activity. One of the main reason for this can be having resident seminar and morning sessions following or before the MMC. We strongly recommend assignment of a separate day for MMC.

In this study, $94.4 \%$ of seniors and all of GPs agreed that the MMCs were blame free, but only $66.2 \%$ of residents and $37.5 \%$ of interns agreed on that $(\mathrm{P}=0.01)$. During MMCs, mostly seniors tend to blame students (interns and residents) for mismanagement. This can be the reason that interns and residents did not strongly agree that it is blame free unlike seniors.

In conclusion, majority of the participants were satisfied with the mortality and morbidity conferences. However, many disagreed on the presence of written term of reference, earlier dissemination of agendas, multidisciplinary team involvement and follow up on the implementation of the forwarded recommendations.

The limitation of the study is that it is a cross sectional study and did not use an in-depth interview. The relatively higher non-response rate of residents is also another limitation.

\section{REFERENCES}

1. Berenholtz SM, Hartsell TL, Pronovost PJ. Learning from defects to enhance morbidity and mortality conferences. American Journal of Medical Quality. 2009 May;24(3):192-5.

2. Pierluissi E, Fischer MA, Campbell AR, Landefeld CS. Discussion of medical errors in morbidity and mortality conferences. Jama. 2003 Dec 3;290(21):2838-42.

3. Orlander JD, Barber TW, Fincke BG. The morbidity and mortality conference: the delicate nature of learning from error. Academic Medicine. 2002 Oct 1;77(10):10016.

4. Aboumatar HJ, Blackledge Jr CG, Dickson C, Heitmiller E, Freischlag J, Pronovost PJ. A descriptive study of morbidity and mortality conferences and their conformity to medical incident analysis models: results of the morbidity and mortality conference improvement study, phase 1. American Journal of Medical Quality. 2007 Jul;22(4):232-8.

5. Bal G, Sellier E, Tchouda SD, François P. Improving quality of care and patient safety through morbidity and mortality conferences. Journal for Healthcare Quality. 2014 Jan;36(1):29-36.

6. Gordon L.Gordons, Guide to the Surgical Morbidity and Mortality Conference. Philadelphia, PA: Hanley and Belfus; 1994.

7. Kirschenbaum L, Kurtz S, Astiz M. Improved clinical outcomes combining house staff selfassessment with an audit-based quality improvement program. Journal of general internal medicine. 2010 Oct 1;25(10):107882.

8. Dupont C, Deneux-Tharaux C, Touzet S et al. Clinical audit: a useful tool for reducing severe postpartum haemorrhages? International Journal for Quality in Health Care. 2011 Jul 6;23(5):583-9.

9. Denis B, Ben Abdelghani M, Peter A, Weiss A-M, Bottlaender J, Goineau J. [Two years of

DOI: http://dx.doi.org/10.4314/ejhs.v30i3.6 
mortality and morbidity conferences in a hospital gastrointestinal endoscopy unit]. Gastroenterology Clin Biol. 2003;27:1100-4.

10. Kim MJ, Fleming FJ, Peters JH, Salloum RM, Monson JR, Eghbali ME. Improvement in educational effectiveness of morbidity and mortality conferences with structured presentation and analysis of complications. Journal of Surgical Education. 2010 Nov 1;67(6):400-5.

11. Risucci DA, Sullivan T, DiRusso S, Savino JA. Assessing educational validity of the Morbidity and Mortality conference: a pilot study. Current surgery. 2003 Mar 1;60(2):204-9.

12. Lecoanet A, Vidal-Trecan $G$, Prate $F$ et al. Assessment of the contribution of morbidity and mortality conferences to quality and safety improvement: a survey of participants' perceptions. BMC health services research. 2016 Dec;16(1):176.

13. Gonzalo JD, Bump GM, Huang GC, Herzig SJ. Implementation and evaluation of a multidisciplinary systems-focused internal medicine morbidity and mortality conference. Journal of Graduate Medical Education. 2014 Mar;6(1):139-46.

14. Higginson J, Walters R, Fulop N. Mortality and morbidity meetings: an untapped resource for improving the governance of patient safety?. BMJ Qual Saf. 2012 Jul 1;21(7):57685.

15. Accreditation Council for Graduate Medical Education. ACGME Program Requirements for Residency Education in Internal Medicine. $2007 . \quad \mathrm{http}: / / \mathrm{www} . \quad$ acgme. org/acWebsite/downloads/RRC_progReq/I40 im 07012007. pdf. 2009.

16. Khine M, Leung E, McGregor JR. A survey of morbidity and mortality review meetings in the general surgical units of the West of Scotland. Scottish medical journal. 2015 Nov;60(4):244-8.

17. Bal G, Sellier E, Tchouda SD, François P. Improving quality of care and patient safety through morbidity and mortality conferences. Journal for Healthcare Quality. 2014 Jan;36(1):29-36.

18. Taylor M, Tesfamariam A. Conducting a multidisciplinary morbidity and mortality conference in the trauma-surgical intensive care unit. Critical care nursing quarterly. 2012 Jul 1;35(3):213-5.

19. Kim MJ, Fleming FJ, Peters JH, Salloum RM, Monson JR, Eghbali ME. Improvement in educational effectiveness of morbidity and mortality conferences with structured presentation and analysis of complications. Journal of Surgical Education. 2010 Nov 1;67(6):400-5. 